\title{
Airway hyperresponsiveness in workers exposed to low levels of irritants
}

\author{
A.M. Kremer*, T.M. Pal**, J.P. Schouten*, B. Rijcken*
}

Airway hyperresponsivesness in workers exposed to low levels of irritants. A.M Kremer, T.M Pal, J.P. Schouten, B. Rijcken. CERS Journals Ltd 1995.

ABSTRACT: The purpose of this study was to assess the association between occupational exposure to low levels of airway irritants, and airway responsiveness to histamine.

In 688 male workers, symptom prevalence was assessed according to the British Medical Research Council (BMRC) questionnaire. All subjects performed a $30 \mathrm{~s}$ tidal breathing challenge test. Airway hyperresponsiveness (AHR) was defined as a $20 \%$ fall in forced expiratory volume in one second $\left(\mathrm{FEV}_{1}\right)$ at $\leq 32 \mathrm{mg} \cdot \mathrm{ml}^{-1}$ histamine. On the basis of job titles and working department, the exposure status of all workers was characterized into seven groups: 1) reference group; 2) white collars; 3) $\mathrm{SO}_{2}, \mathrm{HCl}, \mathrm{SO}_{4}{ }^{2-}$; 4 ) polyester vapour; 5) oil mist and oil vapour; 6) polyamide and polyester vapour; and 7) multiple exposures.

Using multiple logistic regression, no association was found between the exposure groups and a higher prevalence of AHR. A higher prevalence was significantly associated with a low $\mathrm{FEV}_{1}$, a history of allergy, and the presence of chronic respiratory symptoms. Subjects in the $\mathrm{SO}_{2}$ group and the oil mist group with $\leq 5$ exposure years had a lower prevalence of AHR, probably due to pre-employment selection procedures. There was some trend for subjects with more than 5 yrs exposure to polyester vapour and to oil mist and to oil vapour to have a higher prevalence of AHR. Analyses using the dose-response slope according to O'Connor, revealed similar results and provides no additional information.

We conclude that no association could be demonstrated between low grade exposure to airway irritants and airway hyperresponsiveness, and that further research is needed to elucidate this relationship.

Eur Respir J., 1995; 8, 53-61.
Depts of *Epidemiology and Statistics, and **Social Medicine, University of Groningen, Groningen, The Netherlands.

Correspondence: B. Rijcken Dept of Epidemiology and Statistics Ant. Deusinglaan 1 9713 AV Groningen The Netherlands

Keywords: Airway hyperresponsiveness airway irritants occupational exposure

Received: April 11994 Accepted after revision October 151994 Supported by Grant No. 88-32 of The Netherlands Asthma Fund.
Studies of general populations and occupational populations indicate that occupational exposure to fumes and vapours in combination with dust, is a risk factor for developing chronic obstructive lung diseases (COLD), whereas this is less clear for exposure to fumes and vapours without concomitant exposure to dust [1]. It has been reported that exposure to fumes and vapours can be related to airway hyperresponsiveness (AHR). Exposure to high levels of irritants may induce persistent AHR due to mucosal inflammation of the bronchus, whereas exposure to low levels of irritants may provoke an airway narrowing due to a direct effect on the bronchial irritant receptors [2-6]. It has not been investigated whether exposures to irritant gases or fumes at levels commonly found in occupational settings result in obstructive lung diseases $[1,7]$.

We carried out a cross-sectional study of the relationship between exposure to low levels of airway irritants without concomitant dust exposure, and the presence of AHR among workers from synthetic fibre plants. As the level of responsiveness is also associated with smoking, allergy and respiratory symptoms [8,9], we wanted to determine whether the relationship is different for smok- ers, for subjects with a history of allergy, and for subjects with chronic respiratory symptoms. Furthermore, the relationship of duration of exposure to airway responsiveness was investigated. During the 5 years prior to this study, pre-employment selection had taken place for workers who applied for jobs in a working environment with exposure to $\mathrm{SO}_{2}, \mathrm{SO}_{4}{ }^{2-}$ and oil mist. This potential selection bias will be addressed in the Discussion section. In the analyses, we defined responders as subjects with a provocative concentration of histamine producing a $20 \%$ fall in forced expiratory volume in one second $\left(\mathrm{PC}_{20}\right)$ of $\leq 32 \mathrm{mg} \cdot \mathrm{ml}^{-1}$. In addition, we used the doseresponse slope as a continuous variable for airway responsiveness [10], because this index of responsiveness can be calculated for all subjects, and may provide additional information $[11,12]$.

Methods

\section{Study design}

The study was conducted among workers from synthetic fibre plants that belonged to the same industrial 
site, and was carried out from April to July 1989 during working days. The study was approved by the Ethics Board of the Groningen University Hospital and Medical School. Written informed consent was obtained from all participants.

\section{Study population and exposure groups}

Male employees from departments with potential exposure to airway irritants, and a control group from departments presumed to be free from exposure, were invited to participate in the survey. In May 1989 the total number of workers eligible for investigation was 909 men.

On the basis of job titles and working department at the time of the survey, the current exposure status of all workers was characterized. The workers were divided into seven groups.

1) Reference group. This group consisted of workers of the forwarding department, the reelers of the industrial yarn plant, and the texturizers of the carpet yarn plant. These workers were not subjected to exposure to airway irritants.

2) White collar group. The data on workers who were not directly involved in the production of the yarn and fibres were analysed separately. They were process technologists, production instructors, production floor managers and clerical workers.

3) $\mathrm{SO}_{2}, \mathrm{SO}_{4}^{2-}, \mathrm{HCl}$ group. This group consisted of production line workers and maintenance and instrumentation fitters, who could have been exposed to $\mathrm{SO}_{2}$ and $\mathrm{HCl}$ vapour and to $\mathrm{SO}_{4}{ }^{2-}$ and $\mathrm{HCl}$ aerosols, generated during the production process of the para-aramid fibre. Personal sampling ( $7 \mathrm{~h}$ time-weighted average) showed maximum concentrations of $\mathrm{SO}_{2}$ vapour of 0.30 $\mathrm{mg} \cdot \mathrm{m}^{-3}$, of $\mathrm{HCl}$ aerosols of $2.1 \mathrm{mg} \cdot \mathrm{m}^{-3}$, and of $\mathrm{SO}_{4}{ }^{2-}$ aerosols of $0.5 \mathrm{mg} \cdot \mathrm{m}^{-3}$. For certain work operations, peak exposures occur up to $40 \mathrm{mg} \cdot \mathrm{m}^{-3} \mathrm{HCl}$ vapour (averaging time a few minutes) and up to $46 \mathrm{mg} \cdot \mathrm{m}^{-3} \mathrm{SO}_{2}$ vapour (averaging time a few seconds).

4) Polyester vapour group. This group consisted of workers who were involved in the polymerization and polycondensation of the monomers, terephthalic acid and glycol, and cutting up of the polyester polymer. Because of the high temperature $\left(>250^{\circ} \mathrm{C}\right)$ during the polycondensation, some thermodegradation of the polymer can occur. Workers can be exposed to thermodegradation products, such as aldehyde vapours, and to diphenyl diphenyloxide (used as a heat transfer agent) vapour. Personal sampling showed maximum $5 \mathrm{~h}$ time weighted-average concentrations of total aldehyde vapour of $0.04 \mathrm{mg} \cdot \mathrm{m}^{-3}$, primarily consisting of acetaldehyde. No aldehyde peak exposure could be detected (averaging time $30 \mathrm{~min}$ ). Personal sampling of diphenyl diphenyloxide exposure showed $8 \mathrm{~h}$ time-weighted average concentrations up to $7.3 \mathrm{mg} \cdot \mathrm{m}^{-3}(\mathrm{n}=29$; geometric mean (GM) $2.2 \mathrm{mg} \cdot \mathrm{m}^{-3}$ ) under normal conditions, and as a result of an incident up to $48.1 \mathrm{mg} \cdot \mathrm{m}^{-3}\left(\mathrm{n}=14 ; \mathrm{GM} 8.5 \mathrm{mg} \cdot \mathrm{m}^{-3}\right)$. For certain operations, peak exposures to diphenyl diphenyloxide occur; monitoring (averaging time $30 \mathrm{~s}$ ) showed peak exposures up to $60 \mathrm{mg} \cdot \mathrm{m}^{-3}$. Also, during certain operations (process temperatures around $250^{\circ} \mathrm{C}$ ) and as a result of a leak, workers can be exposed to ethylene glycol vapour.

5) Oil mist and oil vapour group. This group was composed of the workers who were involved in winding and stretching (spin-draw winders) of industrial yarn (polyester and polyamide) and of the workers of the spindraw winding and texturizing carpet yarn department. There was exposure to oil mist and oil vapour emanating from the synthetic oil mixture that is applied to the yarn. Monitoring (averaging time 20-30 s) near the machines revealed respirable oil aerosols up to $1.1 \mathrm{mg} \cdot \mathrm{m}^{-}$ 3 in normal situations, and up to $4.4 \mathrm{mg} \cdot \mathrm{m}^{-3}$ during interruptions. Because the yarn is heated (around $180^{\circ} \mathrm{C}$ ), some thermodegradation of components of the oil can occur. The air in the area of one of the three production lines of the winding and stretching department is humidified with a steam humidification system. The air in the area of the other two lines, and the air of the spindraw winding and texturizing department is humidified with a cold water spray system. Exposure to airborne viable materials from the cold water spray system was possible. Results of an occupational exposure study showed low concentrations of airborne Gram-negative bacteria ( $\mathrm{n}=6$; GM 47 colony forming units $(\mathrm{cfu}) \cdot \mathrm{m}^{-3}$ ), of fungi $\left(\mathrm{n}=6\right.$; GM $\left.7.5 \mathrm{cfu} \cdot \mathrm{m}^{-3}\right)$, and of personal exposure to endotoxin $\left(\mathrm{n}=5\right.$; GM $\left.64 \mathrm{pg} \cdot \mathrm{m}^{-3}\right)$ [13].

6) Polyamide and polyester vapour group. This group consisted of the spinners who were involved in spinning of the melted polyamide and polyester chips to yarn, and in exchanging spinning garnitures. Because of the high temperature of the production process $\left(>200^{\circ} \mathrm{C}\right)$, thermodegradation products of the polyamide and polyester polymer could arise. Spinners can be exposed to vapours of these products, for example oligomers, and to lactam vapour. Measurements near the machines showed 150 min time-weighted average concentrations of lactam vapour, with a $\mathrm{GM}$ of $15.9 \mathrm{mg} \cdot \mathrm{m}^{-3}(\mathrm{n}=3)$.

7) Multiple exposures group. This group consisted of maintenance engineers. They were exposed to different airway irritants depending on location within the plant (oil mist and oil vapour, aldehyde and oligomer vapours, lactam, soldering fumes, but no acid aerosols).

\section{Questionnaire}

Data on respiratory symptoms and smoking habits were collected by means of a self-administered Dutch version of the British Medical Research Council (BMRC) standardized questionnaire. Additional questions concerning allergy and work history were included. Subjects were considered to have chronic respiratory symptoms: if they had cough or phlegm production on most days 
or nights for as much as three consecutive months each year during winter (chronic cough or chronic phlegm): if during the previous 3 yrs they experienced more than one period of at least 3 weeks with (increased) cough and phlegm (episodes of bronchitis); if they got short of breath when walking with other people of their own age on level ground (dyspnoea grade III); if their chest sounded wheezing or whistling more than once a year (frequent wheeze); or if they ever had attacks of shortness of breath with wheezing (asthmatic attacks). Subjects were considered to have a history of allergy if they answered yes to one of the following two questions: "Have you ever had hay fever?" and "Do you get eye, nasal or respiratory symptoms if you are exposed to house dust, domestic animals or fungi?"

Nonsmokers were defined as lifelong nonsmokers. Current smokers were defined as those who smoked one cigarette or more per day for at least one year. Exsmokers were those who stopped smoking for at least one month before the examination.

\section{Spirometry}

Spirometry was performed from Monday to Friday between 8:30 a.m. and 4.00 p.m. such that for each department the measurements of the workers were equally distributed over the day, the working week, the shifts and the survey period. Spirometry was performed with a water-sealed spirometer (2400 Pulmonary Function Laboratory; SensorMedics BV, Bilthoven, NL) with automatic data processing. A minimum of three satisfactory forced expiratory manoeuvres were required for each subject. A satisfactory test required that of two manoeuvres the forced vital capacity (FVC) was reproducible within $5 \%$, with a maximum of $300 \mathrm{ml}$ [14]. Measurements were corrected for body temperature, atmospheric pressure, and water saturation (BTPS). In the current paper, the highest values for FVC and forced expiratory volume in one second $\left(\mathrm{FEV}_{1}\right)$ were used for analysis. $\mathrm{FEV}_{1}$ and $\mathrm{FEV}_{1} / \mathrm{FVC}$ were expressed as a percentage of predicted value $\left(\mathrm{FEV}_{1} \%\right.$ pred and $\left.\mathrm{FEV}_{1} / \mathrm{FVC}\right)$ $\%$ pred) using the prediction equations of QUANJER and co-workers [14].

\section{Histamine challenge test}

Airway responsiveness was measured by means of a histamine challenge test. Histamine was dissolved in a phosphate solution: phosphate buffer, $\mathrm{pH} 7.4$ with $0.03 \%$ serum albumin and $0.5 \%$ phenol. Histamine aerosols were generated by a Wiesbaden Doppelinhalator. The nebulizers were calibrated to deliver an output of $0.13 \pm 0.01 \mathrm{ml} \cdot \mathrm{min}^{-1}$ : with a driving pressure of $2.5 \mathrm{bar}$, this required an airflow of $6.5 \mathrm{l} \cdot \mathrm{min}^{-1}$. The nebulizers contained $3 \mathrm{ml}$ of solution at room temperature. The aerosols were delivered via an inspiratory-expiratory valve box and mouthpiece.

The challenge test was not performed on subjects with daily medication for a pulmonary or cardiovascular disease, or on subjects with a prechallenge $\mathrm{FEV}_{1}$ of less than $80 \%$ predicted. The basic protocol is the de Vries modification of the $30 \mathrm{~s}$ tidal breathing method: after pretest with phosphate solution, subjects inhaled sequential aerosols of histamine biphosphate in concentrations of $1,2,4,8,16$ and $32 \mathrm{mg} \cdot \mathrm{ml}^{-1}$ at intervals of $2.5 \mathrm{~min}$ [15]. The $\mathrm{FEV}_{1}$ was measured at 30 and $90 \mathrm{~s}$ after each concentration. The starting concentration of the short protocol was $4 \mathrm{mg} \cdot \mathrm{ml}^{-1}$ histamine. Subjects with a history of asthma-like symptoms, or allergy, or a fall in $\mathrm{FEV}_{1}$ of at least $6 \%$ after phosphate solution, were selected to start at $1 \mathrm{mg} \cdot \mathrm{ml}^{-1}$. All subjects skipped the next concentration if the fall in $\mathrm{FEV}_{1}$ was less than $6 \%$. After a fall of $\mathrm{FEV}_{1} \leq 6 \%$, doubling concentrations were resumed. The test was terminated if a fall in $\mathrm{FEV}_{1}$ of at least $18 \%$ from baseline $\mathrm{FEV}_{1}$ (=prechallenge $\mathrm{FEV}_{1}$ ) occurred, or if the highest concentration had been given. A software program "Broncho-Challenge" (SensorMedics $\mathrm{BV}$, Bilthoven, NL) was used for recording the results of the $\mathrm{FEV}_{1} \mathrm{~s}$ of the challenge test.

\section{Data analysis}

Airway responsiveness was analysed both as a dichotomous and continuous variable. Subjects with a provocative concentration of histamine causing a $\geq 20 \%$ fall in $\mathrm{FEV}_{1}$ of $\leq 32 \mathrm{mg} \cdot \mathrm{ml}^{-1}\left(\mathrm{PC}_{20}\right.$ histamine $\left.\leq 32 \mathrm{mg} \cdot \mathrm{ml}^{-1}\right)$ were considered to be responders; all the others were consi- dered to be nonresponders. $\mathrm{PC}_{20}$ was calculated by log-linear interpolation of the last two data points, with extrapolation up to one doubling concentration. For the continuous variable, the dose-response slope was used [10]. The dose-response slope is expressed as percentage fall in $\mathrm{FEV}_{1}$ per $\mathrm{mg} \cdot \mathrm{ml}^{-1}$ histamine $\left(\% \mathrm{FEV}_{1}\right.$ fall per $\left.\mathrm{mg} \cdot \mathrm{ml}^{-1}\right)$. Distribution analysis showed that the slope variable had a highly skewed distribution. Log and reciprocal transformations of the slope variable were explored to obtain a distribution that was as close to normality as possible. Before the transformation, a constant of 0.3 was added to the slope value to eliminate zero and negative values.

Differences in mean values for the transformed doseresponse slope values between groups were compared using one-way analysis of variance. Differences in prevalence of airway hyperresponsiveness were assessed using the chi-squared test. The association between exposure to airway irritants and the prevalence of AHR was investigated using multiple logistic regression analysis. For the relationship of exposure to the transformed value of the dose-response slope, multiple linear regression analysis was used. Both methods allow simultaneous adjustment for covariates, such as age, smoking habit, allergy by history, chronic respiratory symptoms, and baseline lung function level. Normality plots of the standardized residuals estimated by linear regression analysis, showed that of the transformed slope variable the residuals of the reciprocal of the slope $\left(1 /\left(\% \mathrm{FEV}_{1}\right.\right.$ fall per $\mathrm{mg} \cdot \mathrm{ml}^{-}$ $1+0.3)$ ), were the most normally distributed. Therefore, the results of the analysis with the reciprocal of the doseresponse slope is presented.

Of the calculated odds ratios (ORs), 95\% confidence intervals (CIs) are given. An OR is significant if the CI 


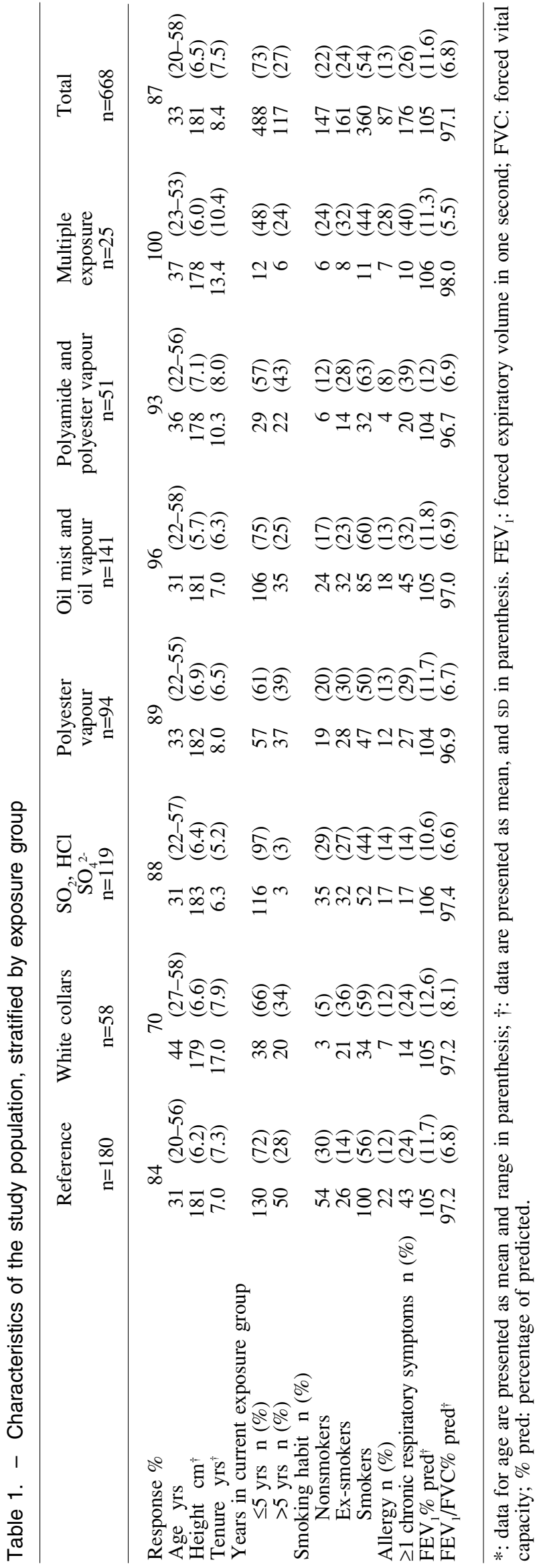

does not include unity. Associations are considered significant at p-values of less than 0.05. All analyses were performed using the Superior Performing Software/PC+ (SPSS, Inc., Chicago, USA) programme (version 4.1).

\section{Results}

Of the 909 workers who were invited, 790 (87\%) participated in the survey. The response rate was $70 \%$ for the white collar group, $84 \%$ for the reference group, and ranged from $88 \%$ for the $\mathrm{SO}_{2}$ group to $100 \%$ for the multiple exposure group. Of these 790 men, 28 were excluded from the analyses because of different cultural, lingual or racial background, which could influence questionnaire response or the results of the lung function test. Furthermore, 51 subjects were excluded from the histamine challenge test: one refused; five subjects had daily medication for a lung disease and 15 for a cardiovascular disease; 22 had a baseline $\mathrm{FEV}_{1}<80 \%$ predicted; and eight had no test for miscellaneous reasons. Eleven subjects had an incomplete challenge test, and for 20 subjects the quality of the test was poor. Of the remaining 680 men, 12 could not be included because of incomplete data on smoking or lung function (no FVC). Thus, data from 668 subjects were available for the analyses.

The study population was young, with $50 \%$ of the subjects younger than 31 yrs (range 20-58 yrs) (table 1). The prevalence of current smoking ranged from $44 \%$ in the $\mathrm{SO}_{2}$ and the multiple exposure group to $63 \%$ in the polyamide and polyester vapour group. A history of allergy was present in $14 \%$ of the nonsmokers, $15 \%$ of the ex-smokers and $12 \%$ of the smokers.

The 119 subjects who did not attend the survey were on average older ( $38 \pm 11 \mathrm{yrs})$ and had a longer tenure

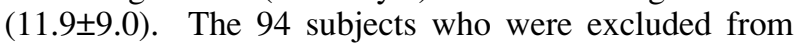
analyses were also on average older ( $37 \pm 12 \mathrm{yrs})$, had a higher prevalence of lifelong nonsmoking $(27 \%)$ and ex-smoking (28\%), a lower prevalence of a history of allergy $(7 \%)$, and a higher prevalence of chronic respiratory symptoms $(29 \%)$. To the extent that pulmonary function data were available $(\mathrm{n}=74)$, the $\mathrm{FEV}_{1} \%$ pred $(93 \% \pm 15 \%)$ and $\mathrm{FEV}_{1} / \mathrm{FVC} \%$ pred $(93 \pm 10 \%)$ were lower in excluded subjects.

\section{Airway hyperresponsiveness}

Airway hyperresponsiveness, defined as a $\mathrm{PC}_{20}$ of $\leq 32$ $\mathrm{mg} \cdot \mathrm{m}^{-1}$, was present in $23 \%$ of the subjects. The reference group had a prevalence of AHR of $26 \%$. The other exposure groups had a lower prevalence, with the exception of the polyester vapour group (28\%). Differences were not statistically significant (table 2). AHR was found significantly more often in smokers $(26 \%)$, subjects with a history of allergy (34\%), and subjects with chronic respiratory symptoms $(35 \%)$. AHR was found more often among older subjects aged 50-59 yrs (32\%) than among younger subjects aged 20-29 yrs (23\%), but this difference did not reach statistical significance. 
Table 2. - The prevalence, the unadjusted odds ratios (ORs) and the adjusted odds ratios with 95\% confidence interval $(95 \% \mathrm{Cl})$ for the prevalence of airway hyperresponsiveness $\left(\mathrm{PC}_{20} \leq 32 \mathrm{mg} \cdot \mathrm{ml}^{-1}\right)$ (adjustment for age, smoking habit, a history by allergy, $\mathrm{FEV}_{1} \%$ predicted and \% $\mathrm{FEV}_{1} / \mathrm{FVC}$ predicted) $(\mathrm{n}=668)$

\begin{tabular}{|c|c|c|c|c|c|c|}
\hline \multirow[b]{2}{*}{ Exposure group } & \multirow{2}{*}{$\begin{array}{c}\text { Total } \\
\mathrm{n}\end{array}$} & \multirow{2}{*}{$\begin{array}{l}\text { AHR } \\
\text { n (\%) }\end{array}$} & \multicolumn{2}{|c|}{$\underline{\text { Unadjusted }}$} & \multicolumn{2}{|c|}{ Adjusted } \\
\hline & & & OR & $95 \% \mathrm{Cl}$ & OR & $95 \% \mathrm{Cl}$ \\
\hline Reference & 180 & $47 \quad(26)$ & 1.0 & - & 1.0 & - \\
\hline White collars & 58 & $15 \quad(24)$ & 1.0 & $0.5-1.9$ & 1.1 & $0.5-2.6$ \\
\hline $\mathrm{SO}_{2}, \mathrm{SO}_{4}{ }^{2-}, \mathrm{HCl}$ & 119 & 21 & 0.6 & $0.3-1.1$ & 0.7 & $0.3-1.2$ \\
\hline Polyester vapour & 94 & $26 \quad(28)$ & 1.1 & $0.6-1.9$ & 1.1 & $0.6-2.1$ \\
\hline Oil mist, oil vapour & 141 & $25 \quad(18)$ & 0.6 & $0.4-1.1$ & 0.5 & $0.3-1.0 *$ \\
\hline $\begin{array}{l}\text { Polyamide vapour and } \\
\text { polyester vapour }\end{array}$ & 51 & 12 (24) & 0.8 & $0.4-1.8$ & 0.9 & $0.4-2.0$ \\
\hline Multiple exposures & 25 & $5 \quad(20)$ & 0.7 & $0.6-1.9$ & 0.8 & $0.3-2.1$ \\
\hline
\end{tabular}

$\mathrm{PC}_{20}$ : provocotive concentration producing a $20 \%$ fall in $\mathrm{FEV}_{1} ; \mathrm{FEV}_{1}$ : forced expiratory volume in one second; FVC: forced vital capacity; \% pred: percentage of predicted; AHR: airway hyperresponsiveness. *: p<0.05

The prevalence of AHR increased significantly with decreasing value of $\mathrm{FEV}_{1} \%$ pred and $\mathrm{FVC} \% / \mathrm{FEV}_{1}$ pred.

Multiple logistic regression analyses revealed that the magnitude of the associations between exposure groups and the prevalence of AHR did not change after adjustment for age, smoking habit, history of allergy, and baseline lung function (table 2). The exposure groups were associated with a lower prevalence of AHR (ORs $<1.0)$ with the exception of the polyester vapour group (OR 1.1). The association with a lower prevalence was statistically significant for the oil mist group (OR 0.5). An additional regression analysis, which included chronic respiratory symptoms as an independent variable, showed similar ORs for the exposure groups as presented in table 2.

Smoking habit and age were not significantly associated with a higher prevalence of AHR, with respective ORs for ex-smoking and smoking of 0.8 (95\% CI 0.41.6) and 1.3 (95\% CI $0.8-2.1$ ), and for age and age $^{2}$ of 0.90 (95\% CI 0.75-1.07), and 1.001 (95\% CI 0.999-1.004). An additional regression analysis without adjustment for lung function level, showed no association between a higher prevalence and older age. Subjects with a history of allergy were responders significantly more often, with an OR of 2.2 (95\% CI 1.3-3.8). Baseline lung function level was significantly associated with
AHR. The prevalence of AHR was 1.5 (95\% CI 1.3-1.9) and 2.5 times higher (95\% CI 1.9-3.4) when the $\mathrm{FEV}_{1}$ and the $\mathrm{FEV}_{1} / \mathrm{FVC}$ ratio were, respectively, $10 \%$ lower than the predicted values.

Stratified logistic regression analyses were performed to investigate whether the association between exposure groups and the prevalence of AHR was different for smokers and nonsmokers, for subjects with and without a history of allergy, and for subjects with and without chronic respiratory symptoms. These analyses did not show marked differences in magnitude of the ORs for the exposure groups between the strata. This indicates that the association between exposure group and the presence of AHR is not different for smokers, for subjects with chronic respiratory symptoms or for subjects with a history of allergy.

The possible association of the duration of the current exposure with the presence of AHR was examined. Logistic regression analyses were carried out, stratified by two duration categories: $\leq 5$ and $>5$ exposure years (table 3 ). For subjects with $\leq 5$ exposure years, the exposure groups were not associated with a higher prevalence of AHR. The oil mist group was significantly associated with a lower prevalence (OR 0.3). For subjects with more than 5 exposure years, the polyester vapour group (OR 2.3) and the oil mist group (OR 2.1)

Table 3. - Prevalence and odds ratios (ORs) with $95 \%$ confidence interval $(95 \% \mathrm{Cl})$ for the prevalence of airway hyperresponsiveness $\left(\mathrm{PC}_{20} \leq 32 \mathrm{mg} \cdot \mathrm{ml}^{-1}\right)$, stratified by exposure years (ORs are adjusted for age, age ${ }^{2}$, smoking habit, allergy by history, FEV\% predicted and \% $\mathrm{FEV}_{1} / \mathrm{FVC}$ predicted $(\mathrm{n}=688)$.

\begin{tabular}{|c|c|c|c|c|c|c|c|c|}
\hline \multirow{3}{*}{ Exposure group } & \multicolumn{8}{|c|}{ Exposure years } \\
\hline & \multicolumn{4}{|c|}{$\leq 5$ yrs $(n=488)$} & \multicolumn{4}{|c|}{$>5$ yrs $(n=180)$} \\
\hline & $\mathrm{n}$ & $(\%)$ & OR & $95 \% \mathrm{Cl}$ & $\mathrm{n}$ & $(\%)$ & OR & $95 \% \mathrm{Cl}$ \\
\hline Reference & 38 & (29) & 1.0 & - & 9 & (18) & 1.0 & - \\
\hline White collars & 11 & (29) & 1.1 & $0.4-3.3$ & 4 & (20) & 1.4 & $0.3-7.0$ \\
\hline $\mathrm{SO}_{2}, \mathrm{SO}_{4}^{2-}, \mathrm{HCl}$ & 21 & (18) & 0.6 & $0.3-1.1$ & 0 & - & $<0.1^{\dagger}$ & - \\
\hline Polyester vapour & 16 & (28) & 1.0 & $0.5-2.1$ & 10 & (27) & 2.3 & $0.7-7.5$ \\
\hline Oil mist, oil vapour & 13 & (12) & 0.3 & $0.1-0.6^{* *}$ & 12 & (34) & 2.1 & $0.6-7.0$ \\
\hline Polyamide vapour and & & & & & & & & \\
\hline polyester vapour & 7 & (24) & 1.0 & $0.4-2.8$ & 5 & (23) & 1.2 & $0.3-4.8$ \\
\hline Multiple exposures & 4 & (33) & 1.2 & $0.3-4.8$ & 1 & (8) & 0.4 & $<0.1-4.2$ \\
\hline
\end{tabular}

$\because$ : no reliable estimation of the OR could be obtained (only three subjects in this stratum); $* *: \mathrm{p}<0.01$. For further abbreviation see legend to table 2 . 
Table 4. - Geometric mean, the unadjusted and adjustedlinear regression coefficients $(\beta)$ for the dose-response slope $1 /\left(\% \mathrm{FEV}_{1}\right.$ fall per $\left.\mathrm{mg} \cdot \mathrm{ml}^{-1}+0.3\right)$ adjustment for age-20, (age-20) ${ }^{2}$, smoking habit, a history by allergy, $(\%-100 \%) \mathrm{FEV}$, predicted and $(\%-100 \%) F_{1} /$ FVC predicted) $(n=688)$

\begin{tabular}{|c|c|c|c|c|c|c|}
\hline \multirow[b]{2}{*}{ Exposure group } & \multicolumn{2}{|c|}{$\% \mathrm{FEV}_{1}$ fall per $\mathrm{mg} \cdot \mathrm{ml}^{-1}$} & \multicolumn{2}{|c|}{ Unadjusted } & \multicolumn{2}{|c|}{ Adjusted } \\
\hline & GM & GSD & $\beta$ & $\mathrm{SE}^{2}$ & $\beta$ & SE \\
\hline Reference & 0.33 & 1.03 & & - & & - \\
\hline White collars & 0.28 & 0.98 & 0.151 & 0.115 & 0.037 & 0.114 \\
\hline $\mathrm{SO}_{2}, \mathrm{SO}_{4}^{2-}, \mathrm{HCl}$ & 0.25 & 0.91 & 0.233 & $0.090 * *$ & 0.202 & $0.082 *$ \\
\hline Polyester vapour & 0.37 & 1.19 & -0.094 & 0.097 & -0.120 & 0.089 \\
\hline Oil mist, oil vapour & 0.30 & 1.08 & 0.082 & 0.086 & 0.096 & 0.078 \\
\hline Polyamide vapour and & & & & & & \\
\hline polyester vapour & 0.33 & 0.84 & 0.003 & 0.121 & -0.037 & 0.111 \\
\hline Multiple exposures & 0.31 & 0.88 & 0.052 & 0.162 & -0.044 & 0.150 \\
\hline Intercept & - & - & 1.588 & 0.057 & 1.432 & 0.094 \\
\hline
\end{tabular}

GSD: geometric standard deviation. For further abbreviations see legend to table 2 . *: $\mathrm{p}<0.05 ; * * \mathrm{p}<0.01$.

were associated with a higher prevalence of AHR, but these associations were not statistically significant.

Associations between exposure groups and prevalence of AHR might have been compromised by the presence of subjects who had recently changed jobs or were employed. Restricting the analysis of table 2 to subjects with at least 6 months of exposure, and an analysis with subjects with at least one year of exposure, did not change the results. ORs for the exposure groups remained essentially the same.

Exclusion of subjects from analyses might have biased the results of table 3 . Of the 94 subjects who were excluded (subjects with different racial or cultural background not included), 32 subjects had $>5$ exposure years, and a relatively large proportion belonged to the reference group: 15 subjects. Taking the relationship of lung function level to airway responsiveness $(57 \%$ of the subjects with an $\mathrm{FEV}_{1}$ of $80-89 \%$ pred were responders) and the lower mean $\mathrm{FEV}_{1} \%$ pred of the excluded subjects into account, one can postulate that exclusion of subjects with $>5$ exposure years might have resulted in a lower prevalence of AHR in the reference group, explaining, at least partly, the stronger association between the prevalence of AHR and the polyester vapour and oil mist group.

Table 5. - Linear regression coefficients $(\beta)$ for $1 /(\%$ $\mathrm{FEV}_{1}$ fall per $\mathrm{mg} \cdot \mathrm{ml}^{-1}+0.3$ ), stratified by exposure years; the coefficients are adjusted for age-20, (age-20)2, smoking habit, a history by allergy, (\%-100\%)FEV 1 predicted and $(\%-100 \%)$ FEV $_{1} /$ FVC predicted $(n=668)$

\begin{tabular}{|c|c|c|c|c|}
\hline \multirow[b]{3}{*}{ Exposure group } & \multicolumn{4}{|c|}{ Exposure years } \\
\hline & \multicolumn{2}{|c|}{$\leq 5 \mathrm{yrs}(\mathrm{n}=488)$} & \multicolumn{2}{|c|}{$\geq 5$ yrs $(n=180)$} \\
\hline & $\beta$ & $\mathrm{SE}^{1}$ & $\beta$ & $\mathrm{SE}$ \\
\hline White collars & 0.076 & 0.144 & 0.009 & 0.221 \\
\hline $\mathrm{SO}_{2}, \mathrm{SO}_{4}^{2-}, \mathrm{HCl}$ & 0.227 & $0.084 * *$ & $1.499^{\dagger}$ & $0.490 * *$ \\
\hline Polyester vapour & -0.028 & 0.104 & -0.354 & $0.176^{*}$ \\
\hline Oil mist, oil vapour & 0.190 & $0.085^{*}$ & -0.153 & 0.176 \\
\hline $\begin{array}{l}\text { Polyamide vapour and } \\
\text { polyester vapour }\end{array}$ & -0.086 & 0.136 & -0.039 & 0.205 \\
\hline Multiple exposures & -0.019 & 0.198 & -0.135 & 0.251 \\
\hline
\end{tabular}

$\dagger=$ three subjects in this stratum; \#: $\mathrm{p}<0.05 ; * *: \mathrm{p}<0.01$. For abbreviations see legend to table 2 .
Dose-response slope

Analyses were also performed with the continuous variable dose-response slope. The geometric mean (GM) value of the dose-response slope was $0.31 \% \mathrm{FEV}_{1}$ fall per $\mathrm{mg} \cdot \mathrm{ml}^{-1}$. This corresponds with an average fall in $\mathrm{FEV}_{1}$ of $10 \%$ at $32 \mathrm{mg} \cdot \mathrm{ml}^{-1}$ histamine. The GM dose-response values of the exposure groups compared with the reference group, correspond with the prevalence of AHR data (tables 2 and 4).

The results of the linear regression analyses confirmed the results of the logistic regression analyses, with the exception of the significance level of the difference between the reference group and the $\mathrm{SO}_{2}$ group and the oil mist group. The value of the intercept of 1.432 corresponds with $0.36 \% \mathrm{FEV}_{1}$ fall per $\mathrm{mg} \cdot \mathrm{ml}^{-1}$ histamine for a 20 year old subject from the reference group with normal lung function. The explanatory variables in the regression analysis (table 4 ) explained $20 \%$ of the variation of the dose-response slope.

Stratified analyses revealed no additional information. In the analysis stratified by duration of exposure, the association between $\leq 5$ yrs of exposure and lower doseresponse slope value was significant for the $\mathrm{SO}_{2}$ group and for the oil mist group (table 5). Subjects from the polyester vapour group and the oil mist vapour with $>5$ exposure years had higher mean dose-response values than those from the reference group. The difference was of borderline significance for the polyester vapour group. These results are in agreement with the logistic regression analysis presented in table 3 .

\section{Discussion}

In this analysis, no association could be demonstrated between exposure to airway irritants encountered in this study and a higher prevalence of AHR. On the contrary, there was a tendency for a lower prevalence among workers exposed to irritants. Adjustment for smoking, allergy by history, and baseline lung function level did not alter the associations between exposure groups and airway responsiveness. Stratified analyses did not indicate that the association was different for smokers, for 
subjects with a history of allergy or chronic respiratory symptoms. Subjects with more than 5 yrs of exposure to polyester vapour and to oil mist and oil vapour had a higher prevalence of AHR than the reference group, but these differences did not reach a significant level. Analyses using a dose-response slope as the parameter for AHR showed similar results and provided no additional information.

It has been reported that single high exposure peaks of gases or fumes induced transient airway hyperresponsiveness or a persistent hyperresponsiveness [6, 7]. There has been no extensive study of whether exposures to gases, vapours or fumes at levels commonly found in occupational settings result in respiratory diseases $[1,7]$. SøYSETH and KongerUd [16] could not demonstrate a relationship between AHR and airborne exposure to fluoride and dust in 339 aluminium potroom workers. KENNEDY et al. [17] found that workers from a metal foundry $(n=45)$ and two cedar sawmills $(n=413)$ had a higher prevalence of AHR than office workers $(n=196)$, but that this difference was not present after adjustment for baseline lung function. In a general population aged 18-73 yrs, BAKKE et al. [18] found no association between occupational airborne exposure to fumes, mists, gases or dusts and a higher prevalence of AHR. The last two studies did not distinguish between exposure to gases, vapours or fumes and airborne dust. Occupational and general population studies do indicate that occupational exposure to irritants is associated with chronic respiratory symptoms [19-24], whereas an association with a lower lung function level could not be demonstrated [25-27], with the exception of the study by $\mathrm{Xu}$ et al. [24]. In the latter study, a general population study in Beijin (China), a significant lower lung function level was found among subjects with occupational exposure to gases/fumes classified as high intensity (=very frequent or daily exposure to high concentrations) compared to subjects with little exposure to gases/fumes.

We, also, could not demonstrate an association between low level exposure to airway irritants and a higher prevalence of AHR, although the workers are potentially exposed to acid aerosols and acid vapour, oil mist and oil vapour, aldehydes/acetaldehydes vapour, glycol and/ or lactam vapour, that are known to produce an irritating effect on the respiratory tract or to induce respiratory symptoms [20, 28-32]. Irritation of the eyes and the mucous membranes have been reported for diphenyl diphenyloxide exposures $[33,34]$. In a previous report, we confirmed the reported association between exposure to irritants and a higher prevalence of chronic respiratory symptoms and the absence of an association with a lower lung function level [35].

A limitation of this study was the power. Power analyses showed that differences in prevalence of AHR between groups should have been at least $15 \%$ to be statistically significant. However, the main finding of this study is not that we could not demonstrate a significant higher prevalence of AHR among exposed workers, but that we were faced with a lower prevalence in the $\mathrm{SO}_{2}$ group and the oil mist group for workers with $\leq 5$ exposure years. The known susceptibility of asthmatics for exposure to
$\mathrm{SO}_{2}[36,37]$, was the reason for the company to have the policy not to employ subjects with a suspected history of asthma-like symptoms in the para-aramide plant, because of the possible exposure to $\mathrm{SO}_{2}$ and $\mathrm{SO}_{4}^{2-}$. This was the case ever since the para-aramide fibre came into production in 1984. Pre-employment selection also took place for workers of the oil mist and oil vapour group. In the years 1984-1989, the medical department of the plant had a tendency not to pass subjects with a history of asthma-like symptoms for employment in a workplace environment with exposure to oil mist and oil vapour. This was necessary because respiratory problems that resembled the syndrome of endotoxin fever had been reported, resulting in transfer of a few workers [13], although the respiratory problems reported were not accompanied by an increased AHR. The other exposure groups were not subjected to pre-employment selections. Our findings may also have been biased by the fact that some workers from the current reference group have an occupational work history at other departments. Moreover, the level of exposure within each exposure group may differ.

The finding that the exposure groups were not associated with a higher prevalence of AHR, might also be because the level of exposure is too low, despite peak exposures during certain task performances, or because the exposure time is too short. In the $10-15$ yrs prior to the study, the company adjusted machines and improved the active ventilation to reduce airborne exposures. If the exposure had the same potency to induce AHR as for example red cedar, isocyanates, or some high molecular weights agents (e.g. flour and cereals), some subjects would have developed asthmatic symptoms within a few years [38]. This would have been noticed by the occupational health department. It is more likely that the airway irritants at exposure levels encountered in this study incite respiratory symptoms, preferentially in subjects with hyperresponsive airways [6], which would also explain the presence of work-related respiratory symptoms as described in a previous report [39].

In addition to pre-employment selection, exclusion of subjects from analyses might have influenced the results. In particular, it might have contributed to the relatively low prevalence of AHR in workers from the reference group with more than 5 exposure years. Thus, the question remains open whether exposure of more than 5 yrs to low levels of irritants, as encountered by the workers of the polyester vapour group and the oil mist group, is associated with a higher prevalence of AHR (table 4), or whether it is partly an artifact caused by exclusion of subjects from analyses.

On average, the response was high. The lowest response was among the white collar workers, in whom no exposure related AHR was to be expected. The major reason for these workers not attending was lack of time. Of the other exposure groups, reasons for not attending varied from no interest, no time (production had higher priority), absence from work due to illness and vacation. The low nonresponse in combination with the variation of reasons not to come, will probably not have caused a strong bias towards no effect. 
In this study, the associations between AHR on the one hand and current smoking, a history of allergy, and chronic respiratory symptoms on the other hand are in agreement with other studies [9]. Also, the lack of a significant association between a higher prevalence of AHR and current smoking after adjustment for lung function level is described by others [17, 18, 40].

In contrast to the $\mathrm{PC}_{20}$, the dose-response slope can be calculated for each subject and, therefore, the doseresponse slope may have a greater statistical power than $\mathrm{PC}_{20}$ [11]. But, the explanatory variables accounted for only $20 \%$ of the variation of the dose-response slope. PEAT et al. [11] found a similar result in their study of a general population sample. Our hypothesis was that analyses with the continuous parameter dose-response slope would show the same associations between airway responsiveness and risk factors as the analyses with the dichotomous variable responder versus nonresponder [12]. The results of the analyses were indeed similar.

In summary, the current analyses could not demonstrate a significant association between exposure to irritants and increased airway responsiveness. The good health surveillance and the achievement of reduced exposure levels might have contributed to this result. However, long-term respiratory health effects might still occur, as suggested by the finding that subjects of the polyester vapour group and the oil mist and oil vapour group with more than 5 exposure years had higher prevalence of airway hyperresponsiveness. No additional information was obtained by using the continuous dose-response slope variable compared to the analyses with the dichotomous airway hyperresponsiveness variable. This study justifies further research to elucidate the relationship between exposure to airway irritants and airway responsiveness.

Acknowledgements: The authors thank all the workers of the synthetic fibre plants who participated for their co-operation, the employees of the Occupational Health Department for their extra efforts, the members of the survey team F. de Wolff and G. Swart for their contribution, J.C. Veltman for programming support, V. Fidler for helpful comments on the statistics, and SensorMedics $\mathrm{BV}$ for the lung function apparatus.

\section{References}

1. Becklake MR. Occupational exposures: evidence for a causal association with chronic obstructive pulmonary disease. Am Rev Respir Dis 1989; 140: S85-S91.

2. Alberts WM, Brooks SM. Advances in occupational asthma. Clin Chest Med 1992; 13: 281-301.

3. Chan-Yeung M, Lam S. Occupational asthma. Am Rev Respir Dis 1986; 133: 686-703.

4. Cockcroft DW. Airway hyperresponsiveness: therapeutic implications. Ann Allergy 1987; 59: 405-414.

5. Dolovich J, Hargreave F. (Editorial). The asthma syndrome: inciters, inducers, and host characteristics. Thorax 1981; 36: 641-644.

6. Fish JE. Occupational asthma: a spectrum of acute respiratory disorders. J Occup Med 1982; 24: 379-386.

7. Brooks SM, Kalica AR. Strategies for elucidating the relationship between occupational exposures and chroic airflow obstruction. Am Rev Respir Dis 1987; 13: 268-273.

8. O'Connor GT, Sparrow D, Weiss ST. The role of allergy and nonspecific airway hyperresponsiveness in the pathogenesis of chronic pulmonary disease. Am Rev Respir Dis 1989; 140: 225-252.

9. Rijcken B, Schouten JP, Mensinga TT, Weiss ST, Vries $\mathrm{K}$ de, Lende $\mathrm{R}$ van der. Factors associated with airways responsiveness to histamine in a population sample of adults. Am Rev Respir Dis 1993; 147: 1447-1453.

10. O'Connor G, Sparrow D, Taylor D, Segal M, Weiss ST. Analysis of dose-response curves to methacholine. Am Rev Respir Dis 1987: 136; 1412-1417.

11. Peat, JK, Salome CM, Berry G, Woolcock AJ. Relation of dose-response slope to respiratory symptoms and lung function in a population study of adults living in Busselton, Western Australia. Am Rev Respir Dis 1992; 146: 860-865.

12. Rijcken B, Schouten JP. Measuring bronchial responsiveness in epidemiology. Eur Respir J 1993; 6: 617618.

13. Kateman E, Heederik D, Pal TM, Smeets M, Smid T, Spitteler M. Relationship of airborne micro-organisms with the lung function and leucocyte levels of workers with a history of humidifier fever. Scand J Work Environ Health 1990; 16: 428-433.

14. Quanjer, Ph. H, Tammeling G.J, Cotes, J.E, Pederson O.F, Peslin R, Yernault J-C. Standardization of lung function testing. Eur Respir J 1993; 6: Suppl 16, 5-40.

15. Vries K de, Goei JT, Booy-Noord H, Orie NGM. Changes during 24 hours in the lung function and histamine hyperreactivity of the bronchial tree in asthmatic and bronchitic patients. Int Arch Allergy 1962; 20: 93-101.

16. Søyseth V, Kongerud J. Prevalence of respiratory disorders among aluminium potroom workers in relation to exposure to fluoride. Br J Ind Med 1992; 49: 125-130.

17. Kennedy SM, Burrows B, Vedal S, Enarson DA, ChanYeung M. Methacholine responsiveness among working populations. Am Rev Respir Dis 1990; 142; 1377-1383.

18. Bakke PS, Baste V, Gulsvik A. Bronchial responsiveness in a Norwegian community. Am Rev Respir Dis 1991; 143: 317-322.

19. Chan-Yeung M, Wong R, MacLean L, et al. Epidemiologic health study of workers in an aluminium smelter in British Columbia. Am Rev Respir Dis 1983; 127: 465-469.

20. Järvholm B, Bake B, Lavenius B, Thiringer G, Vokmann R. Respiratory symptoms and lung function in oil mistexposed workers. J Occup Med 1982; 24: 473-479.

21. Osterman JW, Greaves IA, Smith TJ, Hammond SK, Robins JM, Theriault G. Respiratory symptoms associated with low level sulphur dioxide exposure in silicon carbide production workers. Br J Ind Med 1989; 46: 629-635.

22. Korn RJ, Dockery DW, Speizer FE, Ware, JH, Ferris BG. Occupational exposures and chronic respiratory symptoms: A population-based study. Am Rev Respir Dis 1987; 136: 298-304.

23. Kauffmann F, Drouet D, Lellouch J, Brille D. Occupational exposure and 12 year spirometric changes among Paris area workers. Br J Ind Med 1982; 39: 221-232.

24. Xu X, Christiani DC, Dockery DW, Wang L. Exposureresponse relationships between occupational exposures and chronic respiratory illness: a community-based study. Am Rev Respir Dis 1992; 146: 413-418.

25. Oxhoj H, Andreasen H, Meyer-Henius U. Respiratory symptoms and ventilatory lung function in machine shop workers exposed to coolant-lubricants. Eur J Respir Dis 1982; S118: 85-89. 
26. Kennedy SM, Greaves IA, Kriebel D, Eisen EA, Smith TJ, Woskie SR. Acute pulmonary responses among automobile workers exposed to aerosols of machining fluids. Am J Ind Med 1989; 15: 627-641.

27. Osterman JW, Greaves IA, Smith TJ, Hammond SK, Robins JM, Thériault G. Work-related decrement in pulmonary function in silicon carbide production workers. Br J Ind Med 1989; 46: 708-716.

28. Brabec MJ. Aldehydes and Acetals. In: Clayton GD, Clayton FE eds. Patty's Industrial Hygiene and Toxicology. 3rd edn. New York, John Wiley \& Sons, Inc., 1982; pp. 2629-2669.

29. Ferguson WS, Wheeler DD. Caprolactam vapour exposures. Am Ind Hyg Assoc J 1973; 34: 384-389.

30. Hackney JD, Linn WS, Avol EL. Acid fog: effects on respiratory function and symptoms in healthy and asthmatic volunteers. Environ Health Perspect 1989; 79: 159-162.

31. Parkes WR. Occupational Lung Diseases. 2nd edn. London; Butterworth, 1982; pp. 472-482.

32. Rowe VK, Wolf MA. Glycols. In: Clayton GD, Clayton FE eds. Patty's Industrial Hygiene and Toxicology. 3rd edn. New York, John Wiley \& Sons, Inc., 1982; pp. 3817-3832.

33. Sandmeyer EE. Aromatic hydrocarbons. In: Clayton GD, Clayton FE eds. Patty's Industrial Hygiene and Toxicology. 3rd edn. New York, John Wiley \& Sons, Inc., 1982; pp. 3325-3331.

34. Hefner RE, Leong BKJ, Kociba RJ, Gehring PJ. Repeated inhalation toxicity of diphenyloxide in experimental animals. Toxicol Appl Pharmacol 1975; 33: 78-86.

35. Kremer AM, Pal TM, Boleij JSM, Schouten J, Rijcken B. Airway hyperresponsiveness, chronic respiratory symptom prevalence and lung function in workers exposed to irritants. Occup Environ Med 1994; 51: 3-13.

36. Koenig JQ, Pierson WE, Horike M, Frank R. Effects of inhaled sulfur dioxide $\left(\mathrm{SO}_{2}\right)$ on pulmonary function in healthy adolescents: exposure to $\mathrm{SO}_{2}$ or $\mathrm{SO}_{2}+$ sodium chloride droplets aerosol during rest and exercise. Arch Environ Health 1982; 37: 5-9.

37. Sheppard D, Wong WS, Uehara CF, Nadel JA, Boushey HA. Lower threshold and greater bronchomotor responsiveness of asthmatic subjects to sulfur dioxide. Am Rev Respir Dis 1980; 122: 873-878.

38. Malo J-J, Ghezzo H, D'Aquino C, L'Archêveque J, Cartier A, Chang-Yeung M. Natural history of occupational asthma: relevance of type of agent and other factors in the rate of development of symptoms in affected subjects. J Allergy Clin Immunol 1992; 90: 937-944.

39. Kremer AM, Pal TM, Boleij JSM, Schouten J, Rijcken B. Airway hyperresponsiveness, and work-related symptoms in workers exposed to irritants. Am J Ind Med 1994; (in press).

40. Rijcken B, Schouten JP, Weiss ST, Speizer FE, Lende $\mathrm{R}$ van der. The relationship between airways responsiveness to histamine and pulmonary function level in a random population sample. Am Rev Respir Dis 1988; 137: 826-832. 